\title{
Local Triamcinolone Injection and Oral Steroid in the Patients with Thyrohyoid Syndrome
}

\author{
Nayeon Choi ${ }^{1,2}$ (D) and GilJoon Lee ${ }^{3}$ (D) \\ ${ }^{I}$ Department of Otorhinolaryngology-Head and Neck Surgery, Samsung Medical Center, Sungkyunkwan University School of Medicine, \\ Seoul; and ${ }^{2}$ Department of Otorhinolaryngology-Head and Neck Surgery, Jeju National University Hospital, \\ Jeju National School of Medicine, Jeju; and ${ }^{3}$ Department of Otorhinolaryngology-Head and Neck Surgery, \\ Chilgok Kyungpook National University Hospital, Kyungpook National University School of Medicine, Daegu, Korea
}

\section{갑상설골 증후군 환자에서 국소 스테로이드 주사 및 경구 복용요법의 적용}

최나연 ${ }^{1,2} \cdot$ 이길준 $^{3}$

성균관대학교 의과대학 삼성서울병원 이비인후-두경부외과학교실, ${ }^{1}$ 제주대학교 의과대학 제주대학교병원 이비인후-두경부외과학교실, ${ }^{2}$ 경북대학교 의과대학 칠곡경북대학교병원 이비인후-두경부외과학교실 ${ }^{3}$

Received October 7, 2020

Revised December 2, 2020

Accepted December 18, 2020

Address for correspondence

GilJoon Lee, MD

Department of Otorhinolaryngology-

Head and Neck Surgery,

Chilgok Kyungpook

National University Hospital,

Kyungpook National University

School of Medicine,

807 Hoguk-ro, Daegu 41404, Korea

Tel +82-53-200-2166

Fax $+82-53-200-2027$

E-mail giljoon.lee@gmail.com
Background and Objectives Thyrohyoid syndrome is rare disease characterized by unilateral chronic neck pain on hyoid bone area. Currently, local triamcinolone injection was widely used, but oral steroid treatment was rarely tried. We compared the oral steroid and triamcinolone injection for the thyrohyoid syndrome.

Subjects and Method Patients who had unilateral pain and tenderness at thyrohyoid membrane were enrolled while excluding those with other diseases, such as gastroesophageal reflux, by physical exam and history taking. Patients were treated with oral steroid $(n=15)$ and local triamcinolone injection $(\mathrm{n}=11)$; pain scores based on the pretreatment and post-treatment numeric rating scale (NRS)-11 were compared between the groups.

Results Patients with thyrohyoid syndrome were comorbid with globus (42.3\%), sore throat $(19.2 \%)$, and radiating pain $(15.4 \%)$. In the oral steroid group, posttreatment pain scores $(4.0 \pm$ $2.2)$ significantly improved $(p=0.001)$ more than pretreatment pain scores $(7.7 \pm 1.2)$. In the triamcinolone injection group, posttreatment pain scores $(2.3 \pm 1.7)$ also significantly improved $(p=0.003)$ more than pretreatment scores $(7.5 \pm 1.4)$. None of the patients revealed treatment related complications. Pretreatment scores were not significantly different, but post-treatment scores wre significantly better in the triamcinolone injection group than in the oral steroid group $(p=0.047)$.

Conclusion Oral steroid treatment could be easily performed and have significant effects for patients with thyrohyoid syndrome. Local triamcinolone injection was more effective than oral steroid treatment. Korean J Otorhinolaryngol-Head Neck Surg 2022;65(1):37-40

\section{Introduction}

Thyrohyoid syndrome is characterized by pain which is

This is an Open Access article distributed under the terms of the Creative Commons Attribution Non-Commercial License (https://creativecommons.org/licenses/by-nc/4.0) which permits unrestricted non-commercial use, distribution, and reproduction in any medium, provided the original work is properly cited. worsened by swallowing and neck movement and localized between the lateral side of thyrohyoid membrane. ${ }^{1-3)}$ Patients with thyrohyoid syndrome could also have various non-specific symptoms including globus sense, vague neck pain, and voice change. The point of maximum tenderness varied on this axis, but most commonly was located at the superior cornu 
of thyroid cartilage or the greater cornu of hyoid bone. ${ }^{4)}$

The thyrohyoid membrane is wide fibroelastic membrane which connects between thyroid cartilage and hyoid bone and it is irritated by swallowing. Therefore, it could be chronically damaged and calcified which results in inflammation of hyoid bone and adjacent ligaments and muscles. ${ }^{5,6)}$ In surgical specimen of patients with thyrohyoid syndrome, degenerative damage of hyoid bone were found. ${ }^{6}$

There have not been enough reports about thyrohyoid syndrome, thus treatment method has not been established yet. Surgical removal of hyoid bone with cervical incision were tried in the past, but it was not effective in spite of its invasiveness. ${ }^{1)}$ Nonsteroidal anti-inflammatory drugs medication did not provide satisfactory outcomes in the patients with thyrohyoid syndrome. ${ }^{7)}$ Recently, local triamcinolone acetonide injection has been tried as a non-invasive and effective treatment. ${ }^{8)}$ Precise localization of injection site before procedure is important to inject at exact pain triggering thyrohyoid membrane site. It is sometimes difficult to localization and we suggested oral steroid medication for these patients.

Therefore, we compared the effect of oral steroid and local steroid injection for the patients with thyrohyoid syndrome in this report.

\section{Subjects and Methods}

\section{Study patients}

The patients who were diagnosed as thyrohyoid syndrome were retrospectively enrolled and analyzed $(n=26)$. This retrospective analysis was approved by Institutional Review Board (IRB) of Kyungpook National University Hospital (IRB No. 2020-10-006). Thyrohyoid syndrome was diagnosed by history taking of clinical manifestation and physical examination. Clinical features of thyrohyoid syndrome were chronic (more than 3 months) unilateral dull or pricking pain and tenderness at the lateral side of thyrohyoid membrane. Other disease such as gastroesophageal and laryngopharyngeal reflux disease, Eagle's syndrome, and subacute thyroiditis were excluded. Patients who had reflux finding score more than 7 and reflux symptom index more than 13 were excluded because they were suspected reflux disease. We also excluded the patients diagnosed as gastroesophageal reflux disease by 24 -hour $\mathrm{pH}$ monitoring or esophagogastroscopy.

\section{Evaluation for thyrohyoid syndrome and follow-up periods}

All patients underwent head and neck endoscopic examination and computed tomography to exclude other specific pathology. Blood lab including complete blood count, thyroid function test, erythrocyte sedimentation rate and c-reactive protein were performed to identify other inflammatory disease. After the enrollment of patients with thyrohyoid syndrome, intensity of pain was scored by self-reporting 11-point numeric rating scale (NRS)-11 before and 6 weeks after the treatment.

\section{Treatment protocol of each group}

Before triamcinolone injection, site of maximum tenderness and pain were carefully identified and skin was prepared with alcohol. Triamcinolone acetonide $1 \mathrm{mg}$ (40 mg/mL; Dongkwang Pharm, Seoul, Korea) was injected once using a 25-gauge needle.

The patients of the oral steroid group had $4 \mathrm{mg}$ methylprednisolone (Alvogen Korea, Seoul, Korea) twice a day for 5 days.

\section{Statistical analyses}

Continuous variables between two groups were compared using Mann-Whitney $U$ test and categorical variables were compared using Fisher's exact test. The pretreatment and posttreatment NRS-11 scores of each group were compared by Wilcoxon signed rank test, and pain score between oral steroid treatment group and triamcinolone injection group were compared by Mann-Whitney U test. SPSS for Windows ver. 20.0 (IBM Corp., Armonk, NY, USA) were used for statistical analyses.

\section{Results}

\section{Clinical characteristics of enrolled patients}

The patients were categorized as the oral steroid group ( $n=$ $15)$ and the triamcinolone injection group $(n=11)$. Mean age was $42.9 \pm 2.8$ years in oral steroid group and $39.5 \pm 9.9$ years in triamcinolone injection group (Table 1). Twelve females and 3 males in the oral steroid group, and 4 males and 7 females were in the triamcinolone injection group and gender distribution was not significantly different between two groups. Smokers were $20.0 \%$ of the oral steroid group and $36.4 \%$ of the triamcinolone injection group which did not show statistical difference between two groups. Meanwhile, 60\% and 
Table 1. Comparison of clinical characteristics between patients with thyrohyoid syndrome treated by oral steroid $(n=15)$ and local triamcinolone injection $(n=11)$

\begin{tabular}{lcc}
\hline \multicolumn{1}{c}{ Clinical factors } & Oral steroid & $\begin{array}{c}\text { Triamcinolone } \\
\text { injection }\end{array}$ \\
\hline $\begin{array}{l}\text { Baseline characteristics } \\
\text { Age (years) }\end{array}$ & $42.9 \pm 2.8$ & $39.5 \pm 9.9$ \\
Gender (M:F) & $3: 12(42.9: 63.2)$ & $4: 7(36.4: 63.6)$ \\
Smoking & $3(20.0)$ & $4(36.4)$ \\
Alcohol & $9(60.0)$ & $10(90.9)$ \\
Diabetes mellitus & $0(0)$ & $0(9.1)$ \\
Associated symptoms & & $3(27.3)$ \\
Globus & $8(72.7)$ & $3(27.3)$ \\
Sore throat & $2(13.3)$ & $1(9.1)$ \\
Radiating pain & $3(20.0)$ & $2(18.2)$ \\
Odynophagia & $1(6.7)$ & $3(27.3)$ \\
Outcomes & & $8(72.7)$ \\
Complete resolution & $1(6.7)$ & 0 \\
Partial resolution & $13(86.7)$ & $1(6.7)$ \\
No resolution &
\end{tabular}

Data are presented as the mean \pm SD or $n(\%)$. M: male, $F$ : female

$90.9 \%$ of the oral steroid group and the triamconolone injection group were current alcohol drinkers which showed statistical difference between two groups ( $p=0.004)$. Only one patient of the oral steroid group had diabetes mellitus and incidence of diabetes mellitus was not significantly different.

In the oral steroid group, globus $(72.7 \%)$, radiating pain $(20.0 \%)$, and sore throat $(13.3 \%)$ were accompanied with thyrohyoid syndrome. Globus (27.3\%), sore throat $(27.3 \%)$, and odynophagia (18.2\%) were comorbid in the triamcinolone injection group. These associated symptoms were not significantly different between two groups, and categorical outcomes (complete, partial, and no resolution) of two treatment methods were not significantly different between two groups.

\section{Treatment results of patients with thyrohyoid syndrome}

Pretreatment and posttreatment NRS-11 were described at Table 2. Pretreatment pain score and posttreatment pain score were not significantly different between two groups. In oral steroid group, posttreatment pain score $(4.0 \pm 2.2)$ was significantly improved $(p=0.001)$ than pretreatment pain score $(7.7 \pm$ 1.2). In the triamcinolone injection group, posttreatment pain score ( $2.3 \pm 1.7)$ was also significantly improved ( $p=0.003)$ than pretreatment score $(7.5 \pm 1.4)$. In the oral steroid group, $1(6.7 \%)$ patient had complete resolution of symptom, 13 (86.7\%) had partial response, and 1 (6.7\%) had no improvement. In the tri-
Table 2. Comparison of numeric rating scale-11 pain scales between patients with thyrohyoid syndrome treated by oral steroid $(n=15)$ and local triamcinolone injection $(n=11)$

\begin{tabular}{lccc}
\hline \multicolumn{1}{c}{ Clinical factors } & $\begin{array}{c}\text { Oral } \\
\text { steroid }\end{array}$ & $\begin{array}{c}\text { Triamcinolone } \\
\text { injection }\end{array}$ & p value \\
\hline Pain (visual analogue scales) & & & \\
Pretreatment & $7.7 \pm 1.2$ & $7.5 \pm 1.4$ & 0.540 \\
Posttreatment & $4.0 \pm 2.2$ & $2.3 \pm 1.7$ & 0.047 \\
p-value & 0.001 & 0.003 & \\
\hline Pata are presented as & & &
\end{tabular}

Data are presented as mean \pm SD

amcinolone injection group, 3 (27.3\%) had complete resolution and $8(72.7 \%)$ had partial resolution.

Pretreatment pain score was not different between two groups ( $p=0.547)$, but posttreatment score was better in the local triamcinolone injection group than in the oral steroid group $(p=0.031)$.

\section{Discussion}

Chronic cervical pain had various differential diagnosis such as gastroesophageal reflux disease, chronic tonsilitis, styloid syndrome and subacute thyroiditis. Therefore, thyrohyoid syndrome should be diagnosed by thorough history taking and physical exam to exclude other diseases.

Thyrohyoid ligament is round, wide, and fibroelastic structure at the lateral margin of the thyrohyoid membrane. ${ }^{3,9)}$ The pathogenesis of thyrohyoid syndrome is related with chronic strain and inflammation of the thyrohyoid ligament and adjacent structures including cartilage and bone. ${ }^{6)}$ It is caused by voice abuse, swallowing, neck muscle overuse, and upper limb movements. ${ }^{3,4)}$ The pathognomonic sign of thyrohyoid syndrome is localized pain and tenderness along unilateral thyrohyoid ligament.

Treatment of thyrohyoid syndrome has been varied from surgery to medical treatment. In the report of nonsteroidal anti-inflammatory drugs, $66 \%$ of the patients had symptomatic improvement after treatment. ${ }^{7)}$ Notably, it is especially more effective in the patients with symptom duration less than 6 weeks. However, patients with thyrohyoid syndrome had usually chronic disease course which was difficult to treat by nonsteroidal anti-inflammatory drugs. Surgical removal of greater cornu of hyoid bone with cervical incision were tried in the past. However, complete resolution of pain by surgery was achieved only in the $83.3 \%$ in spite of its invasiveness. ${ }^{1)}$ Recently, local injection of triamcinolone has been main stream to treat the thyrohyoid syndrome. ${ }^{3,8,10)}$ After the injection at the affected thyrohyoid ligament, $74 \%$ of the patients had com- 
plete resolution of symptoms, $15 \%$ had a partial response, and $10 \%$ had no response after local triamcinolone injection. ${ }^{3)}$ It should be performed with careful preoperative physical examination and exact localization of injection site. It could be performed repeatedly in the patient who had unsatisfactory treatment outcome. In the triamcinolone injection group of this study, patients had complete resolution of symptom in $27.3 \%$ and partial response at $72.7 \%$ by one time of injection. Another study about patients with anterior cervical pain demonstrated satisfiable results in all patients after triamcinolone injection and there was no recurrence during $1-5$ years follow periods. ${ }^{10)}$

In our study, we also tried oral steroid treatment which could be easily performed without any invasive procedure. Using oral steroid treatment, $6.7 \%$ had complete resolution and $86.7 \%$ had partial resolution. Complete resolution rate and improvement of NRS-11 pain scales were higher in triamcinolone injection group than in the oral steroid group, but both treatments showed significant improvement of NRS-11 pain scores after treatment. We had no treatment related complication any other problem.

In conclusion, oral steroid and local injection of triamcinolone could be easily and safely performed in the patients with thyrohyoid syndrome. Both treatment methods showed significant effect for the neck pain induced by thyrohyoid syndrome, and local triamcinolone injection showed better outcomes than oral steroid.

\section{Acknowledgments}

None.

\section{Author Contribution}

Conceptualization: GilJoon Lee, Nayeon Choi. Data curation: GilJoon Lee, Nayeon Choi. Formal analysis: GilJoon Lee, Nayeon Choi. Investigation: GilJoon Lee. Methodology: GilJoon Lee, Nayeon Choi. Project administration: GilJoon Lee, Nayeon Choi. Writing original draft: GilJoon Lee, Nayeon Choi. Writing - review \& editing: GilJoon Lee, Nayeon Choi.

\section{ORCIDs}

GilJoon Lee https://orcid.org/0000-0002-3344-1879

Nayeon Choi https://orcid.org/0000-0002-0962-0594

\section{REFERENCES}

1) Brown LA. Hyoid bone syndrome. South Med J 1954;47(11):108891.

2) Robinson PJ, Davis JP, Fraser JG. The hyoid syndrome: A pain in the neck. J Laryngol Otol 1994;108(10):855-8.

3) Stern N, Jackson-Menaldi C, Rubin AD. Hyoid bone syndrome: A retrospective review of 84 patients treated with triamcinolone acetonide injections. Ann Otol Rhinol Laryngol 2013;122(3):15962.

4) Sinha P, Grindler DJ, Haughey BH. A pain in the neck: Lateral thyrohyoid ligament syndrome. Laryngoscope 2014;124(1):116-8.

5) Ilankovan V. An anomaly of the thyro-hyoid articulation. J Laryngol Otol 1987;101(9):959-61.

6) Ernest EA 3rd, Salter EG. Hyoid bone syndrome: A degenerative injury of the middle pharyngeal constrictor muscle with photomicroscopic evidence of insertion tendinosis. J Prosthet Dent 1991;66(1):78-83.

7) Nir D, Hefer T, Joachims HZ. Hyoid bone syndrome and its treatment with nonsteroidal anti-inflammatory drugs. Am J Otolaryngol 1998;19(5):296-300.

8) Kunjur J, Brennan PA, Ilankovan V. The use of triamcinolone in thyrohyoid syndrome. Br J Oral Maxillofac Surg 2002;40(5):450-1.

9) Sellars I. An anatomical study of the subhyoid bursa. J Laryngol Otol 1981;95(5):487-91.

10) Kunachak S. Anterior cervical pain syndromes: Hyoid, thyroid and cricoid cartilage syndromes and their treatment with triamcinolone acetonide. J Laryngol Otol 1995;109(1):49-52. 